\title{
THE DEVELOPMENT OF NEW FRAMEWORKS OF ENGAGEMENT
}

\section{THE IMPORTANCE OF METHODOLOGY}

Our sixth axiom is that a changing diplomatic culture requires the development of new frameworks of engagement. Our goal in this chapter is to clarify some of the conditions under which a values-led dialogue inclusive of religious traditions, and reflecting the decency of ordinary people, can help make multilateralism fit for purpose.

Democratic societies have been founded on two ideas that are in tension with one another. On the one hand, there are shared values - at the minimum, a shared story, a shared understanding of the dangers to be avoided, and shared institutions. On the other hand, nothing is finally fixed. Once the people have taken a major decision, they can always use the same rules to change direction. We create a welfare state; alternatively, we reject 'big government'. Britain can join the EU or leave it again. A state can amend its constitution. The tension between stability and freedom can work well, but only in a context of mutual respect, awareness of shared interests, and serious deliberation about the future.

Our political journey has become more difficult in the 21 st century, for several reasons. There is a mismatch between the 'electoral cycle' and the scale of the problems to be addressed, which require 
long-term strategies. Public debate is often fragmented. 'Everyone has a voice', thanks to social media; but who is listening?

Democratic deliberation about the future is disconnected from reality when, as often happens, we are unable to give due weight to the global dimension of major problems. The global economy is shaped by a complex web of relationships in which the links between cause and effect, between voter preference and real-world outcome, are often impossible to grasp.

Many of the tensions that are a feature of liberal democracy are also relevant in societies based on different political premises. Mutual respect, awareness of shared interests, and serious deliberation about the future are as important for China as for the US.

Some societies are beginning to 'image' the future, not in the sense of making exact predictions, but in the poet Shelley's (2003, p. 677) sense of 'foreknowing the spirit of events'. The 'Global Strategy' ' of the EU, adopted in 2016, looks forward to 'a rulesbased global order with multilateralism as its key principle and the United Nations at its core'. Reviewing the global strategy in 2019, the EU commits itself to upholding international norms; extending multilateralism to new areas; and making multilateral organisations fit for purpose. Post-pandemic - when the worst of the COVID-19 crisis has passed - it is probable that many people will be open to an ambitious imaging of the future.

The stated priorities of Commission President Ursula von der Leyen include a leadership role for the EU in such areas as climate change, the implementation of the SDGs, the reform of the WTO, and defining standards for data protection and the new generation of technologies (von der Leyen, 2019). During the COVID-19 crisis, the Commission is also focusing on public health issues and economic and budgetary strategy.

The horrors of world war and the evils of fascism and communism are not in the memories of today's young people. For them, Europe needs a new raison d'être. I believe dealing with challenges that can be overcome only through collective, multilateral action must be that raison d'être, with climate action first.

(Varadkar, 2020) 
These are the words of the then Irish Taoiseach, Leo Varadkar, in early 2020. Can the EU reach young people, and people who take little interest in politics, with a message that institutions such as the Commission and the European Central Bank are relevant to the daily experience of citizens and reflect the profound vision of reconciliation, solidarity, and peace that lies behind the EU's founding treaties?

In this book, we argue that 'a rules-based global order with multilateralism as its key principle' and 'a new raison d'être for Europe' will depend in part on a cultural transition, a rekindling of dormant aspects of our political and social imagination. New 'places and practices of hope' (Ward, 2020) are a strand to be woven into a comprehensive pattern of change.

As we have argued in earlier chapters, what is not achievable today or tomorrow may become possible in the future. Action even on a limited scale, away from what appears to be the main stage of history, can be the catalyst. A helpful step towards imaging an age of sharing at the global level is to develop the right orientation and methodology for the conduct of diplomacy.

The poet Lorca (1960, p. 382) paints a picture of a sombre, striving 'horseman of the plains' galloping towards distant Cordova. The horseman 'knows the roads'; he is well equipped; but death is watching him from afar. Does Lorca's poem describe our global situation? What is certain is that unless we know the roads and prepare our maps and compasses, we can never even attempt that brave journey across the plains. If issues are not discussed with reference to context and purpose, they will not be solved effectively. Frameworks of engagement need to be created where we can think 30 years ahead, in a global perspective, in the light of what is best in human nature. Unless we make good methodological decisions, the destination of a life worthy of our humanity will remain forever on the distant horizon - lejana y sola, like Cordova in the poem.

\section{THE TIMELINE OF HISTORY}

Before turning to the nuts and bolts of future consultations or negotiations, we will elaborate further on the civilisational issues at stake 
with the help of Osip Mandelstam and Seamus Heaney, two poets who have already been summoned as witnesses in this book.

The external background to the poems of Osip Mandelstam's maturity is the overwhelming change for the worse brought about by war and revolution. An untitled poem of 1918 (Mandelstam, 2008, pp. 202-203) refers to the city of St Petersburg/Petrograd as 'Petropolis'. In calling the much-loved city 'Petropolis', as Pushkin had also done, Mandelstam evokes the world of the Greek polis and links the fate of the city to the course of civilisation itself.

Throughout the poem, Mandelstam addresses a distant star as the 'brother' of Petropolis. The star is a 'wandering fire' or 'giant ship' at a terrible height. The point about the 'terrible height' is that the star and what it may stand for are too far away to make a difference. The star is 'transparent', prozrachnaya, implying ghostliness, a loss of purchase on reality. Since the star seems not to be efficacious, Mandelstam almost begins to doubt its identity. Nevertheless, he ends the poem praying to the star on behalf of the suffering city. There is no exit from the situation other than to appeal to the very source of truth whose significance is called into question in the poem.

If we are to imagine the history of a civilisation as following a timeline, Mandelstam sees himself as living at a late stage, under a drifting or a dying star; the old values are fading.

A star that loses purchase on reality can serve as an image, in certain ways, for the drift in the direction of 'symbolic politics' in many of our democracies and for the wider drift towards international disorder. Seamus Heaney tells us in his Nobel Lecture (Heaney, 1995, p. 14) that his understanding of the place of poetry in society was shaped largely by Mandelstam's example. For Heaney, our historical context at the beginning of the 21 st century is a tired 'aftermath', following colonialism and our 20th-century world wars: 'the documents of civilization have been written in blood and tears ... the inclination is not only not to credit human nature with much constructive potential but not to credit anything too positive in the work of art' (Heaney, 1995, p. 19).

Heaney does not remain in an abject posture. His vision of hope for Ireland is expressed in several individual poems, in the Nobel Lecture, and perhaps above all in the image of 'the tidal wave of justice' in his famous adaptation of a play of Sophocles (Heaney, 1990, p. 77). 
Broadly speaking, Heaney's career is the literary counterpart of the process that led to the Good Friday (Belfast) Agreement in 1998.

For Mandelstam or Heaney, that we are humbled by our history does not rule out new 'political possibilities'. Mandelstam saw his life's work as expressing 'nostalgia for a world culture'. The core of Heaney's Nobel Lecture is that we should 'credit the possibility of a world where respect for the validity of every tradition will issue in the creation and maintenance of a salubrious political space' (Heaney, 1995 , p. 23). In imagining the timeline of history in a new way, we do not rule out Heaney's 'tidal wave of justice' - or as he puts it elsewhere, the 'cloudburst' that transforms everything (Heaney, 1987, p. 47). But barring the political equivalent of a tsunami, a positive change in the pattern of our culture is likely to occur gradually. Therefore, to credit the potential for a 'more salubrious political space' at the global level is to think in terms of a strategy devised for one or two generations.

\section{LIFE LIES IN THE PROCESSES}

In the Introduction, we argued that an effective dialogue about the future international order needs to take into account a number of unavoidable parameters, and that the UN SDGs represent a new approach to global politics in which these parameters are largely implicit:

1. unlike the previous Millennium Development Goals, the SDGs (while considering different national realities, capacities, and levels of development) are applicable to the whole world and not only to 'developing countries'

2. the 193 UN Member States are pledged to ensure that no one will be left behind and to endeavour to reach the furthest behind first

3. they presuppose the interconnectedness of problems and the need for a very broad agenda, integrating economic, social, and environmental dimensions; other global strategies are easily combined with the SDGs

4. the SDGs are action-oriented and look to a cultural change and to greater trust, as well as to material objectives 
5. they seek to engage civil society as well as governments

6. they take as their starting point a shared and realistic understanding of the current global situation

7. they propose a timeline for the achievement of significant progress, running in the first instance to 2030

The SDGs embody, in embryo, a vision of the global citizenship of nation states and a common medium-term plan for humanity. However, the search for agreed criteria for action across political and cultural boundaries is very difficult given the complexity of the subject matter, the need to engage business and civic society, the breaking down of knowledge into specialised fields, new ways of manipulating public debate, and at least to some degree, a loss of trust in our shared future. It is difficult to leap over so many obstacles in one jump.

However, if we make the right intermediate moves in terms of orientation and methodology, we can help unlock the potential for a major future transformation at a global level. In systems biology, there is no privileged level of causation within a multi-level set of interactions (Noble, 2006). A piece of DNA, the environment, and a given phenotype are linked by means of biological networks that serve as pathways or filters. Life lies in the processes. In Chapter 3 , we discussed the concept of 'positive peace' inspired by systems theory. Looking to systems biology for an analogy, we now focus on the processes that restrict harm and enable development.

If conducted under the broad conditions we describe below, the encounter between religion and human values, on the one hand, and global political realities, on the other, has transformative potential within a future life-giving multilateral diplomacy.

The hope that religious and secular leaders will work together and play their role in advancing civilisation is present in many religions and has been expressed with great clarity in the Baha'i Writings:

Our hope is that the world's religious leaders and the world's rulers will unitedly arise for the reformation of this age and the rehabilitation of its fortunes. Let them, after meditating on its needs, take counsel together and, through anxious and full deliberation, administer to a diseased and sorely afflicted world the remedy it requires.

(Bahá'u'lláh, 1973, p. 75) 
Building new frameworks of engagement can prove decisive both for humanity in its present hour of need and for the future of religion and philosophy. To adapt Wittgenstein's image, neither religion nor philosophy should spin in a vacuum with gears that fail to engage the suffering of humankind.

International organisations, backed by governments, should use their convening power to initiate new, multilayered frameworks of engagement, bringing in the representatives of religion. Concepts having some of their roots in religion, such as mercy, patience, solidarity, reconciliation, grace ('a new beginning', the 'given-ness' of peace), and Gandhian satyagraha, as well as the axioms we are proposing in this book, can help us form a deeper understanding of how benign change happens. In support of new forms of consultation, the policy planning sections of foreign ministries can help develop new imaginative resources.

It is true that at the national and international levels, there are a number of existing channels for dialogue between government representatives and the religious communities. However, for the time being, this is a niche area: compartmentalised consultations lacking in political energy are not a likely pathway to a 'civilisational' transformation. It is appropriate, therefore, to explore in more depth how the active engagement of religious communities and others who adopt 'conscience-based' positions or 'life-stances' can contribute to peace building.

\section{CRITERIA FOR THE ENGAGEMENT OF PUBLIC AUTHORITIES WITH RELIGIOUS ACTORS}

As we signalled in the Introduction, there is a strong basis from which to start. Respecting the autonomous existence of religious or belief communities is accepted as an essential aspect of human rights protection. Equality legislation in several jurisdictions covers religious identity. Work has gone forward in recent decades to clarify the legal status of religious or belief communities and identify best practice or 'promising practices'. It is widely accepted that tolerance is an antidote to extremism. 
The religious communities are recognised as having a role in the delivery of public goods such as education, healthcare, and integrating refugees.

Religious actors often play an important part in conflict resolution. Religions cross national frontiers. In the 21 st century, can they help promote international reconciliation - as happened between France and Germany, and Poland and Germany, in the second half of the 20th century but conspicuously failed to happen during World War I?

There is a natural link between conflict resolution and strategies of prevention - such as educating for peace, and illuminating and motivating the broader politics of global peaceful transformation. We argue for a new sensitivity - a 'post-secular sensitivity' - to the role that religion can play in enlarging our understanding of the most pressing challenges of our time and unifying our efforts in response.

If our arguments are accepted, and governments begin to look to the religions for a contribution to a transformational multilateral diplomacy, what are the 'rules of engagement'?

This is an important question because, historically, cooperation between policy makers, other stakeholders, and religious actors has been a sensitive issue; misperceptions on both sides have created tension and alienation. The frameworks we establish should facilitate the effective engagement of public authorities with religious actors. At the same time, religious communities should act responsibly and with integrity in the public sphere. Satisfying these twin objectives will go a long way towards addressing the concerns raised by those who want to keep religions out of policy-making and the work of diplomacy.

Some of the specific questions that arise include:

1. What are the approaches, organisational principles, and values that allow the meaningful and effective engagement of policy makers and other stakeholders with religious actors?

2. Is the engagement with religious actors framed around specific concerns or conflicts, or is it a wider project, more a continuum than a series of events?

3. How can an organisation facilitating dialogue with religious communities and actors safeguard the distinctiveness of intergovernmental responsibilities, as compared to the standpoints and responsibilities of religious dialogue partners? 
4. How do we ensure that a renewed attention to religion as a factor in global affairs and policy-making is oriented towards the dialogue around values, and does not focus on a religion or religions mainly when they are thought to be politically influential, economically strong, or numerically large and growing?

5. Should we try to ensure that the frameworks we establish are an opportunity for the religious traditions themselves to promote renewal - notably, through the greater involvement of women?

6. How can public authorities, while respecting the autonomy of religious communities, take into account their diversity and complexity, as well as the many institutions and associations that flourish under religious auspices? The religions could use the moment creatively in many other ways, for example, by starting new discussions or initiatives on issues of social justice, or by providing new roles for young people and the marginalised, who are often the most credible and effective communicators with their peers at the grassroots level.

7. Should inter-religious dialogue precede engagement with policy makers?

8. Are religious actors competent to negotiate on the main current challenges and, if not, how should they seek to communicate their religious perspective on specific diplomatic challenges?

9. Given that we cannot insist that policy makers engaging in dialogue endorse religion, or embrace the language and discourse of religion, how can we ensure that concepts and modes of action having their roots in religion are kept alive within the emerging culture and do not lose their meaning through secular 'translation'?

We believe that to address these questions will contribute to selfunderstanding on all sides and that answers will be found in a spirit of shared ambition and mutual hospitality. Once the modalities are clear, the detailed subject matter of the conversations that we have in mind will be determined ultimately by public authorities; this follows from the distinction, which we accept and value, between the secular and the religious.

It seems to us that, in principle, the invitation to religious communities to contribute to political deliberations should be openended within each national or regional context; inclusivity is an 
essential criterion. Perhaps submissions from interested religious communities should be sought initially in writing. Consultations with religious communities and actors will need to be extended through time and carefully guided. By a sifting process, the ideas that recur most consistently and persuasively, or seem the most likely to have an impact 'on the ground', can be used in formulating intergovernmental decisions.

The rules to ensure mutual respect, cooperation, and recognition between states and religious communities should always be compatible with broadening participation in a given framework to include other voices and stakeholders ('multi-stakeholder dialogue').

\section{CRITERIA FOR NEW, MULTILAYERED NEGOTIATING PROCESSES}

The new, multilayered negotiating processes that we have in mind should take shape in the light of a number of key requirements that are listed below.

\section{GOVERNMENT 'INVESTMENT'}

One of the main impediments to effective multilateralism, as the authors know from long experience, is that powerful governments do not always invest seriously in multilateral negotiations.

One good measure of the 'level of investment' is access by delegations to the decision-making levels in their home governments. In some international organisations, redundant, it is questionable how much time, effort, and 'political capital' are expended by prime ministers, foreign ministers, governments, and parliamentary committees on the objectives of a given negotiation. When a foreign minister attends a meeting, is it for the sake of that meeting or for wider networking purposes? Is the 'real business' being done elsewhere than in the multilateral forum in question?

When the management of a negotiating process is designed as a routine activity entrusted to mid-ranking diplomats, the inevitable tendency is to avoid innovation. The assumption is that the direction 
of policy has been settled; the role of diplomatic representatives is to project established 'values and interests', uphold alliances, and make space for the 'real negotiations' to go forward elsewhere, usually in very narrow circles. Secretaries of state and ministers do not want to be distracted from other agendas by new ideas 'affirmed from under' (as Seamus Heaney might put it) by delegates to multilateral conferences.

Another measure of commitment to any multilateral process is the allocation of resources, for example, to the budgets of international organisations, or to enable the recruitment of officials and experts to work in a particular area of policy.

\section{A COMPREHENSIVE AGENDA}

In view of the interconnectedness of issues and the need to bring emerging issues to attention, any new framework of engagement should have an open-ended comprehensive agenda, even if the 'sifting process' referred to above eventually leads to the setting of priorities. From the Conference on Security and Cooperation in Europe (CSCE), ${ }^{2}$ we can borrow the concept of a wide agenda broken down into 'baskets' or dimensions. Balancing progress in one basket against progress in another is one of the arts of multilateralism.

\section{A SLOW RHYTHM}

A framework oriented towards clarifying shared values across several 'dimensions' needs to operate to a slow rhythm. The CSCE was conceived as a process and was conducted by means of a chain of conferences in several different capitals. Each conference was extended over years rather than months and included breaks for reflection and consultation. The United Nations Conference on Trade and Development (UNCTAD) has been gathering at ministerial level every four years for half a century or more; though it should be acknowledged that low levels of 'investment' by some players have prevented it from achieving its potential. The UN Law of the Sea Conference followed a similar, slow rhythm. If time is on their side, political leaders and public representatives can become 
accustomed, as they go along, to new ideas and build support for ‘just transitions'.

\section{'MULTIPOLARITY' AND 'TRANSVERSALITY'}

Two common words in today's political discourse are 'multipolarity' and 'transversality'. By 'multipolarity' we mean the interaction and interdependence of many different actors. 'Transversality' suggests that actors in a particular category, such as governments, corporations, international institutions, NGOs, or religious confessions, do not talk only to their direct counterparts, but remain open to forms of dialogue that cut across categories and may prove transformative for themselves.

\section{SUPPORT}

A complex multilateral negotiation needs the support of disinterested officials who serve the process itself. At a minimum, logistical support is essential. In most cases, a secretariat or commission of some kind provides briefing material for delegations. Within the negotiations themselves, conference officers are needed - chairpersons of meetings, thematic coordinators, rapporteurs of meetings, and so on. As a delegate, a diplomat represents his or her government's point of view. As a chair, coordinator, or rapporteur, he or she is expected to act impartially in the role.

\section{ACCESSIBILITY}

There has long been a discussion within international organisations on how best to engage the media. As of now, very few multilateral negotiations are considered newsworthy from week to week or month to month. Interesting, informed, impartial reporting can help to make multilateral diplomacy accessible to the public, which under today's conditions is an important aspect of making it fit for purpose. Encouraging high-quality journalism will be an essential aspect of the multilateral initiatives we have in mind.

However, there is much more that can be done to promote 'accessibility' - by which we mean the awareness and engagement of a broad public. If the conference or process follows a slow rhythm, 
as recommended above, there may be scope to create consultative panels modelled on Ireland's citizens' assemblies. Under this model, an assembly or panel of individuals, including representatives of potentially disadvantaged groups, conducts hearings with a view to identifying possible 'landing places' for the formal negotiations.

The Irish charity First Fortnight creates a space in the cultural calendar where citizens can be inspired through arts and cultural events to talk about mental health issues in a non-scripted manner. The goal is to change people's perceptions about mental health. This can inspire change in public policy, public opinion, and within the creative arts themselves. The First Fortnight model could be adapted to the wider goals of a multilateral negotiating process.

A further option is to create a bespoke digital platform in support of any new process. International organisations already have websites and newsletters. There is scope to increase accessibility by the deployment of new digital tools. For example, 'quadratic voting' is designed to assess the priorities of a large number of individuals on a complex range of options. In the Colorado State legislature in 2019, more than 100 bills with a total price tag of $\$ 120$ million were competing for funding of $\$ 40$ million. Lawmakers were assigned tokens, which they could assign either in a concentrated manner to one or two bills or piecemeal to a broader range of bills. Two votes for the same bill cost four tokens, five votes 25 tokens, and so on ('prices' were squared, hence, 'quadratic voting'): prioritising a small number of bills reduced a lawmaker's influence across the whole package. Like the consensus-building citizens' assemblies in Ireland, or the proportional representation system used in Irish general elections, quadratic voting creates a different dynamic to decision making by simple majorities - and could be used for consultative or 'polling' purposes as well as for making decisions.

\section{THE OUTCOME}

In most cases, the structuring of negotiations implies in itself a broad outcome; so much so, that 'talks about talks' are often the most fruitful stage of any process to resolve differences by dialogue. A good example is the Northern Ireland peace process. The 'three-stranded' 
format of the negotiations anticipated the structure of the Good Friday Agreement (provisions regarding Northern Ireland, the island of Ireland, and the two islands).

In the present context, our orientation is towards a civilisational change, an Axial Age for an interdependent world. Our method is a multilayered negotiating process or processes designed to accommodate what really matters to human beings - conscience-based arguments arising out of religion, human values, life-stances, and philosophical first principles. In structuring a process based on such an orientation and such a methodology, it is essential to reflect in advance on the likely 'product'.

We suggest that any process of the kind we envisage should carry in its 'DNA' potential outcomes at three levels:

1. the gradual definition of new criteria or points of agreement (a 'matrix of principles') in the sphere of international relations

2. the progressive adoption of confidence-building measures

3. a paradigm change over time in our understanding of governance and of the economy

The classic example of a new 'matrix of principles' are the ten principles (the 'Decalogue') set out in the Helsinki Final Act of 1975. These principles established a political platform for an ambitious programme of cooperation.

We interpret 'confidence-building measures' in a broad sense to include new programmes and field missions at the international level, arms control measures, climate-related targets, measures to improve regional connectivity, joint initiatives in the sphere of education, joint humanitarian initiatives, the shared management of water resources; in fact, any measures with demonstrative value in the perspective of 'just transitions' and a future shared understanding of economic and political legitimacy at the global level.

The prospect of a paradigm change in our understanding of governance and of the economy is implicit throughout this book.

The diplomatic work we advocate will reflect a 'theory of change' in harmony with the SDGs but resting ultimately on an evolving cultural or 'anthropological' pattern. We seek a transformation at the level of habits and assumptions, a greater historical and religious literacy, and therefore also an enhanced capacity to work systemically, as our global situation requires. 


\section{CONTINUOUS REVIEW}

We envisage a continuing process as opposed to a once-off negotiation. It follows that reviewing and refining agreed principles and confidence-building measures (CBMs) will be an important part of such an exercise as it goes forward. The review process should be understood as an extra dimension of the dialogue. Agreements may not need to be made legally binding or 'justiciable'.

In the Epilogue, a brief outline is offered of what an all-European initiative might look like if, in the early 2020 s, there were the political will to inaugurate a European regional process reflecting the criteria set out in this chapter. In spanning cultural, religious, and political differences, an all-European conference could inspire parallel initiatives in neighbouring regions: the Mediterranean, Africa, the Middle East, the Silk Road, East Asia.

\section{NOTES}

I The Global Strategy can be viewed on the website of the EU External Action Service at www.eeas.europa.eu.

2 Subsequently, the Organisation for Security and Cooperation in Europe (OSCE).

\section{REFERENCES}

Bahá'u'lláh. (1973). Tablets of Bahá'u'lláh Revealed after the Kitab-i-Aqdas. Compiled by the Research Department of the Universal House of Justice, translated by H. Taherzadeh et al. Haifa: Bahá'í World Centre.

Francis. (2020). 'Letter to Popular Movements and Community Organizations,' Easter Sunday, I2 April.Vatican City: Libreria Editrice Vaticana.

Heaney, S. (1987). 'From the Canton of Expectation', in The Haw Lantern (Collection), p. 46. London: Faber and Faber.

Heaney, S. (1990). The Cure at Troy: A Version of Sophocles's Philoctetes. London: Faber and Faber.

Heaney, S. (1995). Crediting Poetry:The Nobel Lecture 1995. Oldcastle:The Gallery Press.

Lorca, F. (I960). 'Canción de jinete,' in J.M. Cohen (ed.), The Penguin Book of Spanish Verse (revised edition), p. 382. Harmondsworth: Penguin Books.

Mandelstam, O. (2008). ‘Untitled Poem,' in Y.G. Fridstein (ed.), Osip Mandelstam: What Agony! to Search for a Lost Word. Moscow: Bagrius (bilingual edition of Mandelstam's selected poems). 
Noble, D. (2006). The Music of Life: Biology beyond the Genome. Oxford: Oxford University Press.

Shelley, P. (2003). 'A Defence of Poetry', in Z. Leader and M. O'Neill (eds.), Percy Bysshe Shelley: The Major Works, pp. 674-701. Oxford: Oxford University Press.

Varadkar, L. 2020. 'Leo Varadkar: "Thank you to the people of Europe". The Irish Times, 3 I January.

Von der Leyen, U. (20I9). A Union that Strives for More: My Agenda for Europe. Political Guidelines for the Next European Commission 20I9-2024. Brussels: European Commission.

Ward, G. (2020). 'Christian Hope Facing Secular Fatalism,' Loyola Institute Lecture, Trinity College Dublin, 3I January, 2020. 